\title{
Critical illness polyneuromyopathy in septic patients: Is it possible to diagnose it in a bedside clinical examination?
}

\author{
Polineuromiopatia do doente crítico em pacientes sépticos: É possível diagnosticar em \\ um exame clínico à beira do leito? \\ Débora Schmidt',2, Ana Cláudia Coelho ${ }^{1,2}$, Fernando Nataniel Vieira ${ }^{1,2}$, Vitor Félix Torres², Augusto Savi', \\ Silvia Regina Rios Vieira ${ }^{1}$
}

\begin{abstract}
Objective: To determine the sensitivity and specificity of peripheral and respiratory muscle strength tests in diagnosing critical illness polyneuromyopathy (CIPNM), compared with an electrophysiological examination. Methods: Fifty septic patients who required mechanical ventilation for at least five days, and without a previous history of muscle weakness, were included. Peripheral muscle strength was assessed using the Medical Research Council (MRC) score, handgrip strength by dynamometry, and respiratory muscle strength with maximum respiratory pressures. Diagnosis of CIPNM was either confirmed or rejected by an electrophysiological examination. Receiver operating characteristic curve analysis was performed to determine the cut-off values with the best sensitivity (SN) and specificity (SP) of the studied variables in the presence or absence of CIPNM. Results: Patients with CIPNM were older, more critical (APACHE IV/SAPS 3), had a longer hospitalization, required mechanical ventilation for longer, and had a higher rate of intensive care unit readmission. Cutoff values identified CIPNM patients using MRC scores, dynamometry according to sex, maximal expiratory and inspiratory pressures, as well as being confirmed by the electrophysiological examination, with good sensitivity and specificity: < 40 (SN: 0.893 ; SP: 0.955$)$; < 7 kg (SN: 1; SP: 0.909) for men, < $4 \mathrm{~kg}$ (SN: 0.882; SP: 1) for women; <34 $\mathrm{cmH}_{2} \mathrm{O}$ (SN: 0.808; SP: 0.909) and >-40 cmH $\mathrm{O}$ (SN: 0.846 ; SP: 0.909 ), respectively. Conclusion: The MRC score, dynamometry or maximum respiratory pressures can be used to identify patients with CIPNM at the intensive care bedside assessment. The healthcare professional can choose any of the methods studied to evaluate the patient, based on his experience and the resource available.
\end{abstract}

Keywords: Polyneuropathies; muscular diseases; sepsis; muscle strength.

RESUMO

Objetivo: Determinar a sensibilidade (SN) e especificidade (SP) dos testes de força muscular periférica e respiratória no diagnóstico da Polineuromiopatia do Doente Crítico (PNDC) em comparação com o estudo eletrofisiológico. Métodos: Foram incluídos 50 pacientes sépticos, em ventilação mecânica (VM) durante pelo menos cinco dias e sem história prévia de fraqueza muscular. A força muscular foi avaliada utilizando o escore Medical Research Council (MRC), a força de preensão palmar e as pressões respiratórias máximas. 0 diagnóstico de PNDC foi confirmado ou excluído pelo estudo eletrofisiológico. A análise da curva ROC foi realizada para determinar os valores de corte com a melhor SN e SP. Resultados: Os pacientes com PNDC eram mais velhos, mais graves, tiveram hospitalização mais longa, necessitaram de VM por mais tempo e apresentaram maior taxa de readmissão na Unidade de Terapia Intensiva. Os valores de corte identificaram os pacientes com PNDC usando o MRC, a dinamometria de acordo com o sexo, as pressões expiratórias e inspiratórias máximas, também confirmado pelo estudo eletrofisiológico, com boa sensibilidade e especificidade: < 40 (SN: 0.893; SP: 0.955), <7 kg (SN: 1; SP: 0,909) para homens, < $4 \mathrm{~kg}$ (SN: 0,882; SP: 1) para mulheres, $\left\langle 34 \mathrm{CmH}_{2} \mathrm{O}(\mathrm{SN}: 0,808\right.$; SP: 0,909) e >-40 cmH $\mathrm{O}(\mathrm{SN}: 0,846$; SP: 0,909), respectivamente. Conclusão: Tanto o MRC, a dinamometria quanto as pressões respiratórias máximas podem ser usadas para identificar pacientes com PNDC na avaliação à beira do leito, podendo o profissional de saúde escolher qualquer um dos métodos baseado em sua experiência e no recurso disponível.

Palavras-chave: Polineuropatias; doenças musculares; sepse; força muscular.

\footnotetext{
${ }^{1}$ Hospital de Clínicas de Porto Alegre, Porto Alegre RS, Brasil;

${ }^{2}$ Hospital Nossa Senhora da Conceição, Porto Alegre RS, Brasil.

Débora Schmidt (iD) https://orcid.org/0000-0002-8109-6328

Correspondence: Débora Schmidt, Rua Dr. Dario de Bittencourt, 300/704A, Bairro Jardim Europa, Porto Alegre, Brasil, ZIP 91360-390. E-mail: debora. schmidt87@gmail.com

Conflict of interest: There is no conflict of interest to declare.

Received 05 February 2018; Accepted 04 October 2018.
} 
Critical illness polyneuropathy and myopathy are neuromuscular complications that often coexist in the intensive care unit (ICU) and their main characteristic is muscle weakness $^{1,2}$. Critical illness polyneuromyopathy (CIPNM) is the neuromuscular condition most commonly acquired in the ICU, occurring in $25 \%$ to $63 \%$ of patients who required mechanical ventilation for at least a week $\mathrm{w}^{3,4,5,6,7}$. In patients with sepsis, this incidence varies between $50 \%$ and $100 \% \%^{8,9,10,11}$.

Development of weakness during a stay in the ICU correlates with an increase in morbidity and mortality in both the short and long term ${ }^{12,13,14}$. At present, there is no specific treatment for this complication. However, early diagnosis may be important for future treatments, as a reduction in nervous and muscular excitability can be observed on the second day after admission into the $\mathrm{ICU}^{10,15}$.

An electrophysiological examination allows the earliest diagnosis of CIPNM ${ }^{16}$. However, this method is not available in all ICUs and it requires the presence of a qualified professional to perform the test and interpret the results. Peripheral muscular strength assessment, using the Medical Research Council (MRC) muscle strength score and by dynamometry, is widely used and accepted for diagnosing muscle weakness acquired in the ICU. This bedside test is easy to perform and has good intra- and inter-observer reliability ${ }^{13,17,18,19}$, but it requires the patient to be able to understand and execute the examiner's instructions. This capability is often compromised by a reduced state of consciousness and use of sedatives ${ }^{1,18,20}$, both frequent in critical patients, leading to a delay in the diagnosis.

Sensitivity and specificity of tests for identifying muscle weakness in patients who are not fully cooperative remain unclear. However, there is limited evidence for respiratory and skeletal muscle weakness being related to respiratory pressures ${ }^{5,21}$.

We aimed to determine the sensitivity and specificity of tests for peripheral and respiratory muscle strength in diagnosing CIPNM, compared with the electrophysiological examination.

\section{METHODS}

A prospective study was carried out in an ICU in the south of Brazil. The research was approved by the institutional review board and all those responsible for the patients involved in the study signed the written informed consent prior to their inclusion in the study.

All patients between 18 and 75 years old, diagnosed with sepsis, severe sepsis or septic shock, which required invasive mechanical ventilation for five days or more, were selected for the study.

The exclusion criteria were previous muscular weakness, neurological or musculoskeletal diseases, diabetes mellitus, chronic kidney disease, human immunodeficiency virus and alcohol abuse.

The ICU patients were followed daily and the patients who met the inclusion criteria were followed until the final outcome (hospital discharge or death). The severity of the disease was evaluated using the Acute Physiology and Chronic Health Evaluation (APACHE) IV and the Simplified Acute Physiology Score (SAPS) 3, on the date of the ICU admission.

When the patient was alert, cooperating and capable of following verbal commands, a physical evaluation was performed, starting by measuring the respiratory muscle strength, followed by upper and lower limb muscle strength, and handgrip strength.

\section{Respiratory muscle strength}

Respiratory muscle strength was measured using the subatmospheric [maximal inspiratory pressure (MIP)] and superatmospheric pressure [maximal expiratory pressure (MEP)] generated during an effort against the occluded airway. The recommendations of the American Thoracic Society/ European Respiratory Society Statement on Respiratory Muscles Testing were followed ${ }^{22}$ and a digital manovacuometer with a self-calibration system was used. For the analysis, the best of three acceptable values were considered.

\section{Peripheral muscle strength}

Peripheral muscle strength was evaluated using the MRC score. Twelve muscle groups in the superior (wrist extensors, elbow flexors and shoulder abductors) and inferior (ankle dorsal flexors, knee extensors and hip flexors) extremities were tested. A score between 0 (full paralysis) and 5 (normal strength) was attributed to each muscle group, where the total score totaled 60 points and indicated the absence of muscle weakness. Immediately thereafter, handgrip strength was evaluated using dynamometry (Saehan Smedley Hand Dynamometer, Belgium). For this purpose the patient was seated, with the elbow at $90^{\circ}$ and the handgrip effort had to be maintained for at least three seconds. The best value of the dominant hand was used for the analysis.

\section{Electroneuromyography}

Electroneuromyography was the tool used to diagnose CIPNM. The examination was carried out at the ICU with a portable Neurosoft system (Neuro - MEP - Micro), using surface electrodes to capture and analyze sensory and motor nerve conduction through electrical stimulation. Concentric needle electrodes were used for the electromyography analysis of distal and proximal muscles. The same investigator, who had no knowledge of the clinical condition of the patient, carried out the examination in all cases.

According to the electroneuromyography, the patients were classified into two groups: patients who had alterations compatible with the CIPNM diagnosis (CIPNM group) and patients who did not have alterations that indicated CIPNM (non-CIPNM group).

\section{Statistics}

The Statistical Package for Social Science, version 17.0 software was used for the statistical analysis. In order to compare 
the CIPNM and non-CIPNM groups, the Student's t test, or Wilcoxon-Mann-Whitney test, were used for the independent samples. For the qualitative variables, Fisher's exact test or Pearson's chi-square tests $\left(\chi^{2}\right)$ were used, depending on whether the frequency distribution was normal or not. To evaluate the associations between the quantitative variables, Pearson's or Spearman's correlation were used and, for the qualitative variables, $\chi^{2}$. Receiver operating characteristic curve analysis was used to determine the cut-off values with the best sensitivity and specificity of the MRC score, dynamometry, and maximal respiratory pressures in the presence or absence of CIPNM. The values of the area under the curve, with $95 \%$ confidence interval, positive predictive value (PPV) and negative predictive value (NPV) were reported. The analyzed variables had their values adjusted for an average age of 53.74 years and SAPS of 65.42; $\mathrm{p}<$ 0.05 was considered statistically significant.

\section{RESULTS}

During the study, 647 patients admitted to the ICU were diagnosed with sepsis, severe sepsis, or septic shock; of these, 181 were included in the study, and 120 (66\%) died before evaluation. The patient follow-up flowchart is shown in Figure 1.

Fifty patients took part in the muscle strength evaluation and in the electroneuromyographic study, and $56 \%$ of these patients were diagnosed with CIPNM. Patient characteristics are shown in Table 1. Patients with CIPNM were older and

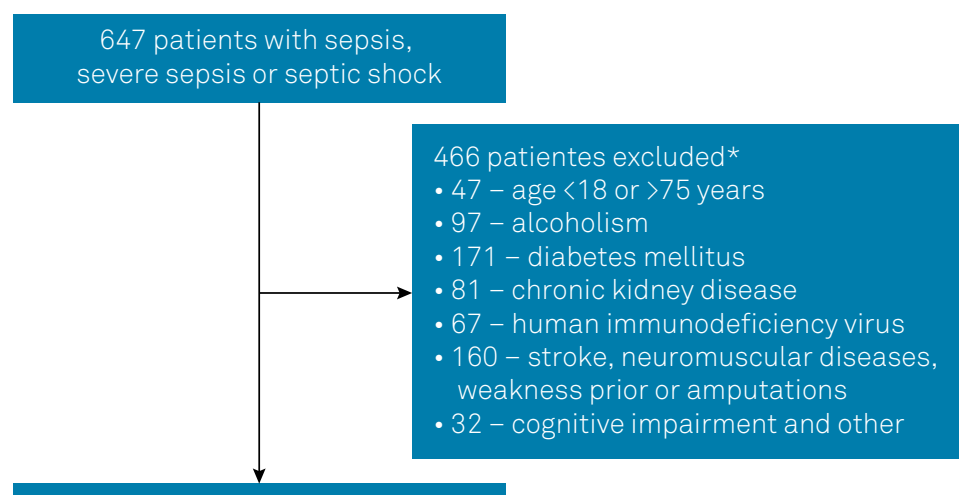

181 patients met inclusion criteria

120 deaths before evaluation

6 - no consente

5 - unable to perform the evaluation

50 patients evaluated

Figure 1. Patients' screening flowchart. *Some patients met more than one exclusion criterion.

Table 1. Characteristics of the patients.

\begin{tabular}{|c|c|c|c|}
\hline Characteristic & CIPNM $(n=28)$ & Non-CIPNM $(n=22)$ & $p$-value \\
\hline Age & $57.8 \pm 14.9$ & $48.6 \pm 14.2$ & 0.03 \\
\hline Female & $17(61 \%)$ & $11(50 \%)$ & 0.45 \\
\hline White & 25 (89\%) & $20(91 \%)$ & 0.85 \\
\hline Diagnosis & & & 0.47 \\
\hline Sepsis & $1(4 \%)$ & $6(27 \%)$ & \\
\hline Severe sepsis & $11(39 \%)$ & $5(23 \%)$ & \\
\hline Septic shock & $16(57 \%)$ & $11(50 \%)$ & \\
\hline Site infection & & & 0.66 \\
\hline Respiratory & $22(78 \%)$ & $18(82 \%)$ & \\
\hline Abdominal & $5(18 \%)$ & $4(18 \%)$ & \\
\hline Urinary tract & $1(4 \%)$ & 0 & \\
\hline APACHE IV & $77.7 \pm 22.1$ & $65.7 \pm 16.4$ & 0.04 \\
\hline SAPS 3 & $68.8 \pm 14.9$ & $61.1 \pm 10.5$ & 0.05 \\
\hline Hospital stay (days) & 69 (32-183) & $34.5(12-98)$ & $<0.0001$ \\
\hline ICU stay (days) & $40(10-126)$ & $14(7-28)$ & $<0.0001$ \\
\hline ICU readmission & $8(29 \%)$ & $1(4 \%)$ & 0.028 \\
\hline Hospital mortality & $10(36 \%)$ & $3(14 \%)$ & 0.077 \\
\hline
\end{tabular}


Table 2. Muscle strength.

\begin{tabular}{lccc} 
Variable & CIPNM & Non-CIPNM & p value \\
\hline MIP $\left(\mathrm{CmH}_{2} \mathrm{O}\right)$ & $29.6 \pm 1.9$ & $52.3 \pm 2.1$ & $<0.0001$ \\
MEP $\left(\mathrm{cmH}_{2} \mathrm{O}\right)$ & $25.3 \pm 1.9$ & $48.2 \pm 2.1$ & $<0.0001$ \\
MRC score & $27.1 \pm 2.1$ & $51.4 \pm 2.3$ & $<0.0001$ \\
Dynamometry $(\mathrm{kg})$ & $2.5 \pm 0.96$ & $13.6 \pm 1.1$ & $<0.0001$
\end{tabular}

CIPNM: Critical illness polyneuromyopathy; MIP: Maximal inspiratory pressure; MEP: Maximal expiratory pressure; MRC: Medical Research Council. Values expressed as mean \pm standard error. Results corrected for age and SAPS 3.

had more serious illness, according to the APACHE IV and SAPS 3 scores. Patients with CIPNM had longer ICU and hospital stays and a higher rate of readmission into the ICU. Their respiratory muscle strength, upper and lower limb strength according the MRC score (in all tested muscular groups), and handgrip strength were significantly lower than those without CIPNM (Table 2 and Figure 2).

The ability to identify CIPNM patients was determined by evaluating sensitivity and specificity (Figure 3 ). For peripheral muscle strength, the cut-off was 40 points in the MRC score, with a sensitivity of 0.893 ; specificity of 0.955 ; PPV $96 \%$; and NPV $84 \%$.

Because handgrip strength is influenced by sex, we determined a specific dynamometry cut-off value for each

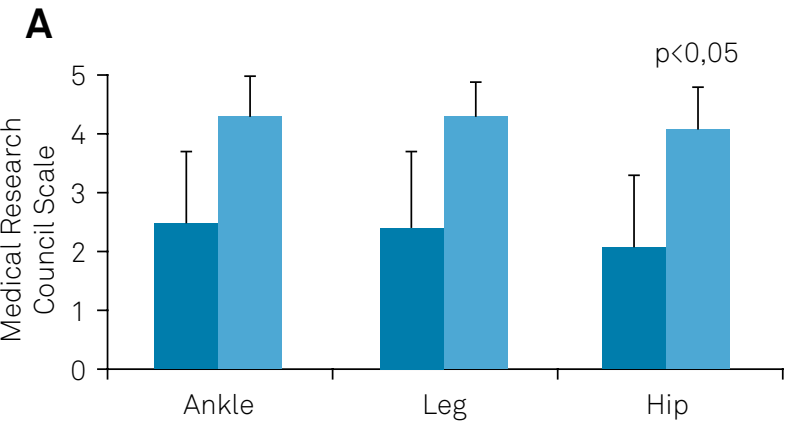

B

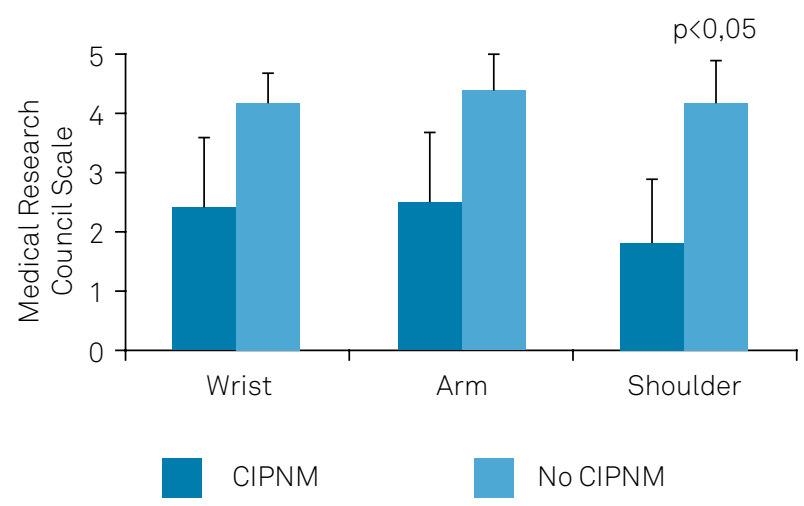

Figure 2. Skeletal muscle strength in lower limbs (A) and upper limbs (B), according to Medical Research Council. CIPNM -

Critical Illness Polyneuromyopathy.
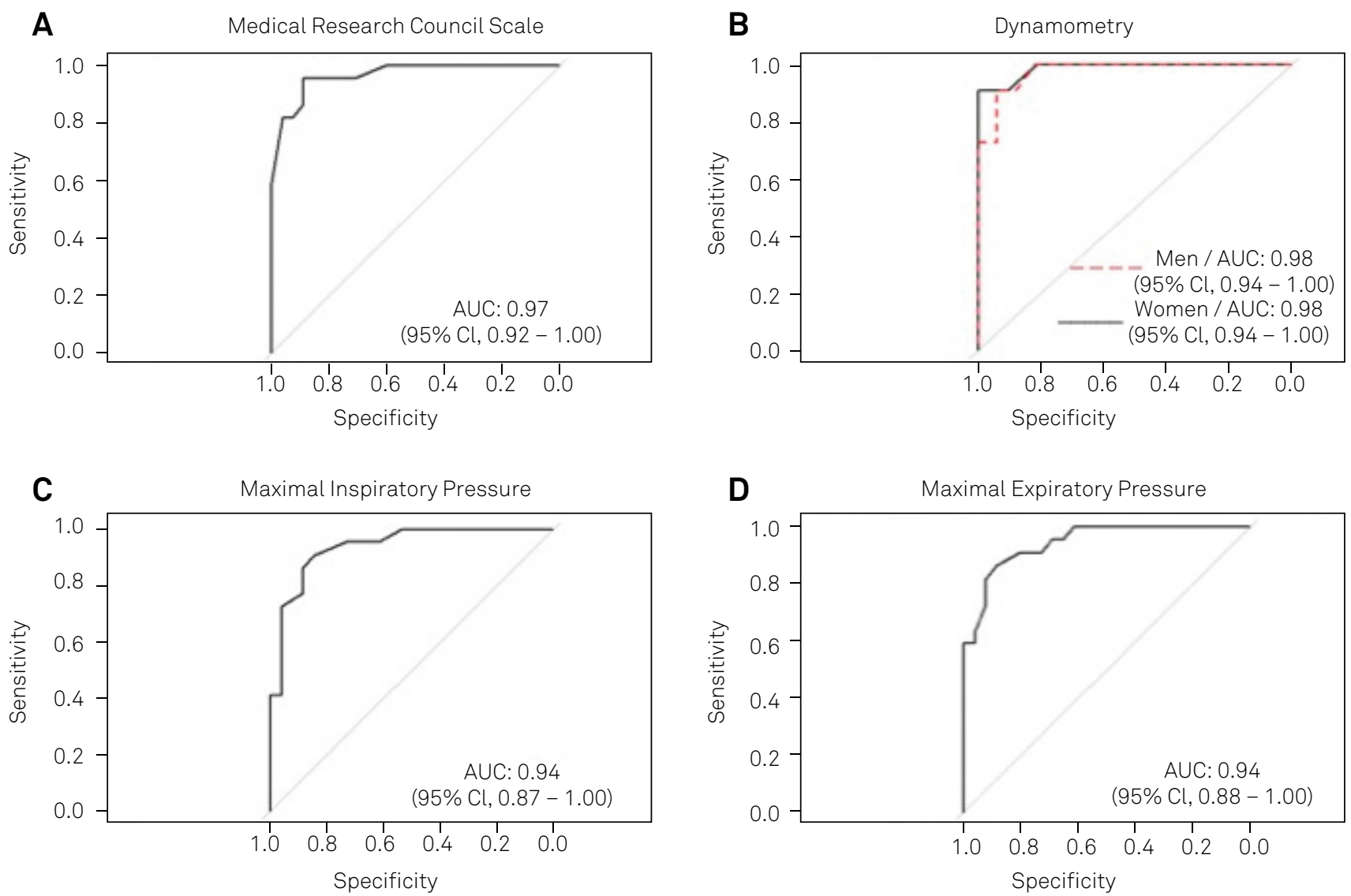

AUC: area under the curve

Figure 3. Receiver operating characteristic curves of the Medical Research Council Scale (A), dynamometry values for men and women (B), Maximal Inspiratory Pressure (C) and Maximal Expiratory Pressure (D). 
sex. For women, a $4 \mathrm{~kg}$ cut-off ensured a sensitivity of 0.882 ; specificity 1; PPV 100\%; and NPV 85\%. For men, the cut-off was $7 \mathrm{~kg}$, with a sensitivity of 1; specificity 0.909; PPV 92\%; and NPV $100 \%$.

For respiratory muscle strength, MIP at $-40 \mathrm{cmH}_{2} \mathrm{O}$ showed a sensitivity of 0.846; specificity 0.909; PPV 92\%; and NPV $83 \%$, and MEP at $34 \mathrm{cmH}_{2} \mathrm{O}$ had a sensitivity of 0.808 ; specificity 0.909; PPV 91\%; and NPV 80\%.

\section{DISCUSSION}

Tests for evaluating peripheral and respiratory muscle strength (MRC score, dynamometry, and maximal respiratory pressures) were sensitive and specific for diagnosing CIPNM in a bedside evaluation of septic patients.

All three methods evaluated were effective in identifying CIPNM cases confirmed by an electrophysiological study, using the following cut-off points: MRC score $<40$ points, handgrip strength $<4 \mathrm{~kg}$ for women and $<7 \mathrm{~kg}$ for men, $\mathrm{MIP}>-40 \mathrm{cmH}_{2} \mathrm{O}$, and $\mathrm{MEP}<34 \mathrm{cmH}_{2} \mathrm{O}$. Therefore, either the MRC score or dynamometry, or the evaluation of maximal respiratory pressures can be used to diagnose CIPNM, as they were shown to be equivalent in sensitivity and specificity. Therefore, ICU professionals may use the test that is available to them, or select an alternative test that minimizes risk to the patient.

Ali et al. ${ }^{13}$ determined cut-off values for the MRC score and dynamometry in ICU patients with muscle weakness. An MRC score < 4 for all muscle groups-i.e., a total score $<48$-indicated the presence of muscle weakness. For dynamometry, the cut-off values found were $11 \mathrm{~kg}$ for men and $7 \mathrm{~kg}$ for women. The values are useful to identify patients with "ICU-acquired weakness", that is, a weakness that developed during the ICU stay that has no plausible cause other than critical illness ${ }^{23}$. However, the evaluation of peripheral muscle strength alone cannot detect the cause of the weakness. The weakness in the patients evaluated in our study was secondary to a polyneuropathy that was documented in an electrophysiological examination (critical patient polyneuropathy). We report lower cut-off values than those found by Ali et $\mathrm{al}^{13}$. We attribute this difference to our sample being patients with confirmed CIPNM.

It is important to define criteria that allow the practical identification of CIPNM at the bedside, considering that electroneuromyographic examinations are not available in all ICUs and require the presence of a qualified professional to perform the test and interpret the results. The MRC score is easily applied, is widely used, has no costs, and shows good reproducibility ${ }^{13,17,18,19}$. In addition, it requires only a short time for the evaluation, but it does require the patient to be awake and cooperative, which can limit its application in patients who are under the effect of sedatives or in delirious states ${ }^{18,20}$. Moreover, the MRC scale has important limitations, such as poor discrimination and a potential ceiling effect ${ }^{17}$.
Handgrip strength correlates with the strength of other muscle groups ${ }^{24}$, and it has been suggested as a global functional physical test ${ }^{21}$. It stands out for being a lowcost method that is easily performed and provides objective results. However, like the MRC score, it depends on the patient's cooperation and may be influenced by factors such as hand edema, which is very common in ICU patients.

Respiratory muscle strength can be measured in the ICU using the maximal respiratory pressure recorded following a volitional maneuver starting from the functional residual capacity $^{22}$. However, this may be difficult in ICU patients who are not cooperative. For such patients, a nonvolitional method using a one-way valve is a good alternative ${ }^{25,26}$.

In our study, both MIP and MEP successfully identified CIPNM patients by cut-off points. Because they are widely used by physiotherapists in ICUs, we suggest that they be the method of choice for patients who are not fully awake and cooperative. We believe that the evaluation of maximal respiratory pressures allows an earlier diagnosis compared with methods that evaluate peripheral muscle strength, and it can be used as soon as respiratory drive is restored, but we did not evaluate this in our study.

The results of our study show that in daily practice, we can use the MRC assessment, maximal respiratory pressures or dynamometry, all with the same power to identify patients with CIPNM. The physiotherapist can, based on his experience and the availability of equipment, choose any of the methods used in our study to evaluate his patient. We suggest the following use:

1) MIP or MEP: for evaluation of patients who cannot collaborate with an evaluation of peripheral muscle strength;

2) MIP, MEP or dynamometry: for patients with physical barriers to the MRC evaluation (eg. catheters, external fixators, fractures, etc.);

3) MRC, dynamometry, MIP or MEP: to assess collaborative patients without physical barriers to the evaluation.

Our study has some limitations. Firstly, because we studied a specific group of patients (with sepsis), we do not know whether these findings are applicable to other populations of ICU patients with different risk factors for developing CIPNM. Secondly, as our evaluation was performed when the patient was awake and collaborative, it was not possible to identify early cases of CIPNM. Based on this, we suggest that future studies should test the power of maximal respiratory pressures to screen CIPNM in an early evaluation, without the requirement for the patient to be awake, which would enable earlier intervention and possibly allow a faster recovery for our critical patients.

In conclusion, the MRC score, handgrip, and maximal respiratory pressures are three sensitive and specific test alternatives to identify CIPNM in septic patients evaluated at the bedside in the ICU. The choice of method will depend on the availability of equipment and trained personnel to perform each evaluation. It appears that maximal respiratory pressures are the best method for patients who are not totally awake. 
1. Hodgson $\mathrm{CL}$, Tipping CJ. Physiotherapy management of intensive care unit-acquired weakness. J Physiother. 2017 Jan;63(1):4-10. https://doi.org/10.1016/j.jphys.2016.10.011

2. Latronico N, Rasulo FA. Presentation and management of ICU myopathy and neuropathy. Curr Opin Crit Care. 2010 Apr;16(2):123-7. https://doi.org/10.1097/MCC.0b013e328336a229

3. Garnacho-Montero J, Amaya-Villar R, GarcíaGarmendía JL, Madrazo-Osuna J, Ortiz-Leyba C. Effect of critical illness polyneuropathy on the withdrawal from mechanical ventilation and the length of stay in septic patients. Crit Care Med. 2005 Feb;33(2):349-54. https://doi.org/10.1097/01.CCM.0000153521.41848.7E

4. Bolton CF. Neuromuscular manifestations of critical illness. Muscle Nerve. 2005 Aug;32(2):140-63. https://doi.org/10.1002/mus.20304

5. De Jonghe B, Bastuji-Garin S, Durand MC, Malissin I, Rodrigues P, Cerf C et al. Respiratory weakness is associated with limb weakness and delayed weaning in critical illness. Crit Care Med. 2007 Sep;35(9):2007-15. https://doi.org/10.1097/01.ccm.0000281450.01881.d8

6. Letter MA, Schmitz PI, Visser LH, Verheul FA, Schellens RL, Op de Coul DA et al. Risk factors for the development of polyneuropathy and myopathy in critically ill patients. Crit Care Med. 2001 Dec;29(12):2281-6. https://doi.org/10.1097/00003246-200112000-00008

7. Leijten FS, Harinck-de Weerd JE, Poortvliet DC, Weerd AW. The role of polyneuropathy in motor convalescence after prolonged mechanical ventilation. JAMA. 1995 Oct;274(15):1221-5. https://doi.org/10.1001/jama.1995.03530150045032

8. Bercker S, Weber-Carstens S, Deja M, Grimm C, Wolf S, Behse F et al. Critical illness polyneuropathy and myopathy in patients with acute respiratory distress syndrome. Crit Care Med. 2005 Apr;33(4):711-5. https://doi.org/10.1097/01.CCM.0000157969.46388.A2

9. Hund E. Neurological complications of sepsis: critical illness polyneuropathy and myopathy. J Neurol. 2001 Nov;248(11):929-34. https://doi.org/10.1007/s004150170043

10. Tennilä A, Salmi T, Pettilä V, Roine RO, Varpula T, Takkunen O. Early signs of critical illness polyneuropathy in ICU patients with systemic inflammatory response syndrome or sepsis. Intensive Care Med. 2000 Sep;26(9):1360-3. https://doi.org/10.1007/s001340000586

11. Witt NJ, Zochodne DW, Bolton CF, Grand'Maison F, Wells G, Young GB et al. Peripheral nerve function in sepsis and multiple organ failure. Chest. 1991 Jan;99(1):176-84. https://doi.org/10.1378/chest.99.1.176

12. Latronico N, Shehu I, Seghelini E. Neuromuscular sequelae of critical illness. Curr Opin Crit Care. 2005 Aug;11(4):381-90. https://doi.org/10.1097/01.ccx.0000168530.30702.3e

13. Ali NA, O'Brien JM Jr, Hoffmann SP, Phillips G, Garland A, Finley JC et al. Acquired weakness, handgrip strength, and mortality in critically ill patients. Am J Respir Crit Care Med. 2008 Aug;178(3):261-8. https://doi.org/10.1164/rccm.200712-18290C
14. Sharshar T, Bastuji-Garin S, Stevens RD, Durand MC, Malissin I, Rodriguez $P$ et al. Presence and severity of intensive care unitacquired paresis at time of awakening are associated with increased intensive care unit and hospital mortality. Crit Care Med. 2009 Dec;37(12):3047-53. https://doi.org/10.1097/CCM.0b013e3181b027e9

15. Khan J, Harrison TB, Rich MM, Moss M. Early development of critical illness myopathy and neuropathy in patients with severe sepsis. Neurology. 2006 Oct;67(8):1421-5. https://doi.org/10.1212/01.wnl.0000239826.63523.8e

16. Wieske L, Verhamme C, Witteveen E, Bouwes A, Dettling-Ihnenfeldt DS, Schaaf $M$ et al. Feasibility and diagnostic accuracy of early electrophysiological recordings for ICU-acquired weakness: an observational cohort study. Neurocrit Care. 2015 Jun;22(3):385-94. https://doi.org/10.1007/s12028-014-0066-9

17. Kress JP, Hall JB. ICU-acquired weakness and recovery from critical illness. N Engl J Med. 2014 Apr;370(17):1626-35. https://doi.org/10.1056/NEJMra1209390

18. Hough $C L$, Lieu BK, Caldwell ES. Manual muscle strength testing of critically ill patients: feasibility and interobserver agreement. Crit Care. 2011;15(1):R43. https://doi.org/10.1186/cc10005

19. Connolly BA, Jones GD, Curtis AA, Murphy PB, Douiri A, Hopkinson NS et al. Clinical predictive value of manual muscle strength testing during critical illness: an observational cohort study. Crit Care. 2013 Oct;17(5):R229. https://doi.org/10.1186/cc13052

20. Vanpee G, Hermans G, Segers J, Gosselink R. Assessment of limb muscle strength in critically ill patients: a systematic review. Crit Care Med. 2014 Mar;42(3):701-11. https://doi.org/10.1097/CCM.0000000000000030

21. Cottereau G, Dres M, Avenel A, Fichet J, Jacobs FM, Prat D et al. Handgrip Strength Predicts Difficult Weaning But Not Extubation Failure in Mechanically Ventilated Subjects. Respir Care. 2015 Aug;60(8):1097-104. https://doi.org/10.4187/respcare.03604

22. American Thoracic Society/European Respiratory Society. ATS/ERS Statement on respiratory muscle testing. Am J Respir Crit Care Med. 2002 Aug;166(4):518-624. https://doi.org/10.1164/rccm.166.4.518

23. Stevens R, Marshall S, Cornblath D, Hoke A, Needham D, Jonghe B et al. Jonghe Bd, Ali N, Sharshar T. A framework for diagnosing and classifying intensive care unit-acquired weakness. Crit Care Med. 2009;37:S299-308. https://doi.org/10.1097/CCM.0b013e3181 b6ef67

24. Samuel D, Rowe P. An investigation of the association between grip strength and hip and knee joint moments in older adults. Arch Gerontol Geriatr. 2012 Mar-Apr;54(2):357-60. https://doi.org/10.1016/j.archger.2011.03.009

25. Truwit JD, Marini JJ. Validation of a technique to assess maximal inspiratory pressure in poorly cooperative patients. Chest. 1992 Oct;102(4):1216-9. https://doi.org/10.1378/chest.102.4.1216

26. Tzanis G, Vasileiadis I, Zervakis D, Karatzanos E, Dimopoulos S, Pitsolis T et al. Maximum inspiratory pressure, a surrogate parameter for the assessment of ICU-acquired weakness. BMC Anesthesiol. 2011 Jun;11(1):14. https://doi.org/10.1186/1471-2253-11-14 